\title{
OUTLIER DIAGNOSTIC IN GEODETIC INTERSECTION
}

\author{
Jana IŽVOLTOVÁ ${ }^{1, *}$, Vladimír KOŤKA $^{1}$ \\ ${ }^{1}$ Department of Geodesy, Faculty of Civil Engineering, University of Žilina, Univerzitná 8215/1, 01026 \\ Žilina, Slovak Republic. \\ corresponding author: jana.izvoltova@fstav.uniza.sk, +421-4-1513 5555.
}

\section{Abstract}

Residuals are differences between observed and predicted variables. This paper describes outlier detection method with using studentized internal and external residuals, which was applied to find extreme values in dataset that comes from the planar intersection method. The detected outlier is analysed by the statistical hypothesis testing, where critical value is defined as a quantil of Studentized distribution.
\end{abstract}

\section{Keywords:}

Residual;

Gauss-Markov model; Intersection method; Least square method; Studentized residual.

\section{Introduction}

Outlier diagnostic is an important part of data analysis. It is not a new problem either in statistics and geodesy and many authors deal with this problem in their publications. For example, Koch describes general method of outlier detection in a univariate dataset, Zvára uses outlier labelling methods in s linear regression and Seo compares the particular outlier detection methods. Filzmoser, Rousseeuw and Leroy apply outlier detection in robust regression and Schafer describes the application of the outlier detection methods in continuous multivariate dataset.

The paper deals with a process of outlier diagnostic in geodetic model consisting of given directions and angular and distance measurements done in planar intersection problem as one can see in section 4.

In common, outlier diagnostic is based on identifying the measurement mistakes and gross errors and aims to the statistical hypothesis testing to disconfirm the anticipated affirmation. After Seo review, outliers have deleterious effects on statistical analysis, because they can increase error variance and reduce the power of statistical tests, and if non-randomly distributed, they can decrease normality and finally outliers can seriously bias or influence estimates that may be of substantive interest.

Inductive statistic provides several methods for outlier detection, which can be classified to formal and informal tests. Most formal tests need test statistics for hypothesis testing and often use the residuals to identify the deviation of an extreme value from the assumed distribution. Informal methods generate an interval for outlier detection instead of hypothesis testing.

Residuals are estimates of experimental error obtained by subtracting adjusted values from the observed ones. The adjusted value used to be an estimation of mathematical model, constructed from the experimental data. A careful look at residuals can tell us whether our assumptions are reasonable and our choice of model is appropriate [1]. In the process of detecting outliers, studentized residuals occupy a significant role. They are represented by the quotient resulting from the division of a residual by an estimate of its standard deviation. It belongs to a Student's t-statistic, with the estimate of error varying between points. This is an important technique in the process of detecting outliers. It is named in honour of William Sealey Gosset, who wrote under the pseudonym Student, so dividing by an estimate of scale is called studentizing, in analogy with standardizing and normalizing.

\section{Residuals in a linear model}

Consider the linear Gauss-Markov model, a residual is defined as a difference between the measured value $\mathbf{y}$ and the predicted one $\widehat{\mathbf{y}}$, which can be obtained by a parameter estimation method:

$\mathbf{e}=\mathbf{y}-\widehat{\mathbf{y}}=\mathbf{y}-\mathbf{A} \widehat{\boldsymbol{\beta}}$ 
where $\mathbf{A}$ is a design matrix of known $n \times k$ coefficients. The best unbiased estimation of a $k \times 1$ vector of unknown parameters $\hat{\boldsymbol{\beta}}$ and its variance-covariance matrix $\mathbf{D}(\widehat{\boldsymbol{\beta}})$ is estimated by the minimizing squared residuals as follows:

$\widehat{\boldsymbol{\beta}}=\left(\mathbf{A}^{T} \mathbf{A}\right)^{-1} \mathbf{A}^{T} \mathbf{y}$

$\mathbf{D}(\widehat{\boldsymbol{\beta}})=\sigma^{2}\left(\mathbf{A}^{T} \mathbf{A}\right)^{-1}$

and the estimations of a residual and its variance is then computed according to the following formulas:

$\widehat{\mathbf{e}}=-(\mathbf{I}-\mathbf{R}) \mathbf{y}$,

$\mathbf{D}(\widehat{\mathbf{e}})=\sigma^{2}(\mathbf{I}-\mathbf{R})$,

where $\sigma^{2}$ is an unit variance, which follows from the Least square and is computed according to the formula:

$\sigma^{2}=\frac{\mathbf{e}^{T} \mathbf{e}}{n-k}$

where $n-k$ is file redundancy and $\mathbf{R}=\mathbf{A}\left(\mathbf{A}^{T} \mathbf{A}\right)^{-1} \mathbf{A}^{T}$ is a projection matrix or so called "hat" matrix, whose elements are as follows:

$r_{i j}=a_{i j}\left(\mathbf{A}^{T} \mathbf{A}\right)^{-1} a_{i j}^{T}$.

In comparison with (3 b), the variance estimation of $i$-th residual $\hat{e}_{i}=a_{i j} \beta_{i}-y_{i}$ is equated according to the formula:

$\hat{\sigma}_{e}=\sigma^{2}\left(1-r_{i i}\right)=\sigma^{2}-\sigma^{2} a_{i j}\left(\mathbf{A}^{T} \mathbf{A}\right)^{-1} a_{i j}^{T}$

A number of the model (1) assumptions pertain directly to residuals normality and homoscedasticity. The residuals normality can be confirmed by the hypothesis testing, where one can formulate the general hypothesis $H_{0}$ : residuals are normally distributed; against the alternative one $H_{1}$ : residuals are not normally distributed. To find the critical value in the process of hypothesis testing, Chí-quadrate test and Kolmogorov - Smirnov test is often used. The most simple method used to verify the residuals homoscedasticity is plotting residuals to visualize their dispersion against $\widehat{\boldsymbol{\beta}}$.

\section{Standardized and studentized residual}

As mentioned before, one can assume that the residuals are normally distributed $\widehat{\mathbf{e}} \approx N\left(0, \sigma_{e}^{2}\right)$ with mean zero $\mu_{e}=0$ and variance $\sigma_{e}^{2}$ and vary from a point to point. In comparison with a following standard value:

$z=\frac{x-\mu}{\sigma}$ 
as a parameter of the standard normal distribution $N(0,1)$, the residual transforms into the standardized residual $e_{s i}$ as follows:

$e_{s i}=\frac{\widehat{e}_{i}-0}{\sigma_{e}}=\frac{\widehat{e}_{i}}{\sigma_{e}} \in N(0,1)$.

In the conformity with the formula (6) the standardized residual of $i$-th value is equal to the equation:

$e_{s i}=\frac{\hat{e}_{i}}{\sigma \sqrt{1-r_{i i}}}$

Complementary to the idea of the standardized residuals, there are the internally studentized residuals, computed as follows:

$e_{j i \text {,inter }}=\frac{\hat{e}_{i}}{\sigma_{-i} \sqrt{1-r_{i i}}}$

where $\sigma_{-i}$ is an estimation of the standard deviation if the estimation procedure is run without the $i$-th observation.

As mentioned before, Studentized residuals are used to identify outliers in the file of measurements in the technique based on an assumption that the $i$-th measurement is outlying, if the expected value of $i$-th residual is not zero $E\left(e_{i}\right) \neq 0$. According to this theory, studentized residual of $i$-th point is estimated from the model constructed for $n-1$ values and so $\sigma_{-i}$ will be standard deviation computed besides the $i$-th row of variance-covariance matrix. The diagonal elements of projection matrix $r_{i i}$ represent distances from the centroid to a point and are computed according to the formula:

$r_{i i}=a_{i j}\left(\mathbf{A}_{i}^{T} \mathbf{A}_{i}\right)^{-1} a_{i j}^{T}$.

They are positive and less than 1, while the trace of projected matrix is equal to the number of unknown parameters plus 1 :

$0<r_{i i}<1$

$\operatorname{tr}(\mathbf{R})=\sum_{i=1}^{n} r_{i i}=u+1$

Studentized residual of $i$-th value belongs to the Student distribution with the parameter $t(n-u-1)$ and defined probability $\mathrm{P}=1-\alpha$. On the base of internally studentized residuals, the externally studentized residuals, so called Jacknife residuals are computed according to the formula:

$e_{j i \text {, xter }}=e_{j i \text {,inter }} \sqrt{\frac{n-u}{n-u-1-e_{j i \text {,inter }}}}$. 
Jacknife residuals are compared with the $t(n-u-1)$ quantil of Student distribution with the $n-u-1$ degrees of freedom to confirm the $i$-th value to be an outlier. The estimation of unknown parameter $\hat{\boldsymbol{\beta}}_{-i}$ by the Least square method in the Gauss-Markov model, which is constructed by missing out the $i$-th value is similar to the formula (1) and equal:

$\widehat{\boldsymbol{\beta}}_{-i}=\left(\mathbf{A}_{-i}^{T} \mathbf{A}_{-i}\right)^{-1} \mathbf{A}_{-i}^{T} \mathbf{y}_{-i}$,

and the unknown parameter $\widehat{\boldsymbol{\beta}}_{-i}$ is computed in dependence on estimation $\widehat{\boldsymbol{\beta}}$, which is obtained from the origin model, constructed for $n$ measurements [4]:

$\hat{\boldsymbol{\beta}}_{-i}=\hat{\boldsymbol{\beta}}+\frac{e_{i}}{1-r_{i i}}\left(\mathbf{A}^{T} \mathbf{A}\right)^{-1} a_{i}$.

\section{Conclusions}

The paper presents methodology to analyse the file of measured values by identifying outliers with the method of studentized residuals, which is often used to detect extreme values in the geodetic measurements processed by a method of parameter estimation. The advantage of such a used method is in diagnostic outliers in geodetic datafile along with the estimation process of by the mathematical modelling. By detecting the outliers, the another problem originates, what to do with such as contaminated observations: to delete value, because of an error exists, improve model, usually through additional variables, leave this contaminated observation, because of small size of a file, switch a robust regression approach or change the methodology and make a new observation file.

\section{Acknowledgement}

This article is the result of the implementation of the project: "Innovation and internationalization of education - the means to increase the quality of the University of Zilina in the European educational space (ITMS: 26110230079) supported by the Research \& Development Operational Programme funded by the ERDF.

This article is the result of the implementation of the project VEGA No. 1/0597/14 "Analysis of methods used to measure the unconventional railway track construction from the point of view of accuracy and reliability" supported by the Scientific Grant Agency of the Ministry of Education, science, research and sport of the Slovak Republic and the Slovak Academy of Sciences.

\section{References}

[1] Engineering Statistics Handbook. NIST/SEMATECH e-Handbook of Statistical Methods, 2006, [cit. 09.2014]. Available at: http://www.itl.nist.gov/div898/handbook/.

[2] ZVÁRA, K.: Identifikace odlehlých pozorování v lineární regresi. Česká statistická společnost, sborník Robust 1982, p. 120., Kost.

[3] TVRDíK, J.: Analýza vícerozměrných dat. Ostravská univerzita, Přírodovědecká fakulta, Ostrava, 119 p., 2003.

[4] ANDĚL, J.: Matematická statistika. SNTL Praha, 346 p., 1985.

[5] $\mathrm{KOCH}, \mathrm{K}$. R.: Parameterschätzung und Hypothesentests in linearen Modellen. Vierte bearbeitete Auflage, Dümmlers Verlag, Bonn, 382 p., 2004.

[6] GAŠINEC, J. - GAŠINCOVÁ, S. - SABOVÁ, J. - WEISS, G.: Adjustment of position geodetic networks by robust estimations. 14. konference Společnosti důlních měřičů a geologů. Ostrava VŠB TU, 2007, p. 1-14. ISBN 9788024816548.

[7] KOŤKA, V. - ŠíMA, J.: Geodetické zameranie a konštrukcia nepravidel'ných telies, Acta Montanistica Slovaca. 10, 2005, 2, 136-139, ISSN 1335-1788. 
[8] VILLIM, A.: Estimation of Variance Components of 2D Geodetic Network. TRANSCOM $2009-8^{\text {th }}$ European conference of young research and scientific workers, Žilina 2009, p. 109-114, ISBN 978-80-554-0030-3.

[9] FILZMOSER, P.: A multivariate outlier detection method. In S. Aivazian, P. Filzmoser, and Yu. Kharin, editors, Proceedings of the Seventh International Conference on Computer Data Analysis and Modelling, volume 1, pp. 18-22, Belarusian State University, Minsk, 2004.

[10]SCHAFER, J. L.: Outlier detection and editing procedures for continuous multivariate data. Working paper No. 2008-07. Department of Statistics, Princeton University, 2003, pp. 26. [cit. 09.2014]. Available at: http://opr.princeton.edu/papers/opr0307.pdf.

[11]WELSCH, W. M. - HEUNECKE, O.: Models and terminology for the analysis of geodetic monitoring observations. Official Report of the Ad-Hoc Committee of FIG Working Group 6.1. The International Federation of Surveyors (FIG), Frederiksberg, Denmark, p. 43, 2001. 